\title{
Combination of stromal cell-derived factor-1 and collagen-glycosaminoglycan scaffold delays contraction and accelerates reepithelialization of dermal wounds in wild-type mice
}

\section{Citation}

Sarkar, Aparajita, Soner Tatlidede, Saja Sandra Scherer, Dennis P. Orgill, and François Berthiaume. 2010. "Combination of Stromal Cell-Derived Factor-1 and CollagenGlycosaminoglycan Scaffold Delays Contraction and Accelerates Reepithelialization of Dermal Wounds in Wild-Type Mice." Wound Repair and Regeneration 19 (1) (December 6): 71-79. doi:10.1111/j.1524-475x.2010.00646.x.

\section{Published Version}

doi:10.1111/j.1524-475X.2010.00646.x

\section{Permanent link}

http://nrs.harvard.edu/urn-3:HUL.InstRepos:32659609

\section{Terms of Use}

This article was downloaded from Harvard University's DASH repository, and is made available under the terms and conditions applicable to Other Posted Material, as set forth at http:// nrs.harvard.edu/urn-3:HUL.InstRepos:dash.current.terms-of-use\#LAA

\section{Share Your Story}

The Harvard community has made this article openly available.

Please share how this access benefits you. Submit a story.

\section{Accessibility}




\title{
Combination of stromal cell-derived factor-1 and collagen- glycosaminoglycan scaffold delays contraction and accelerates reepithelialization of dermal wounds in wild-type mice
}

\author{
Aparajita Sarkar, $\mathbf{M S}^{1,2,3}$, Soner Tatlidede, $\mathbf{M D}^{2,4}$, Saja Sandra Scherer, $\mathbf{M D}^{5}$, Dennis $\mathbf{P}$. \\ Orgill, $\mathbf{M D}, \mathrm{PhD}^{5}$, and François Berthiaume, $\mathrm{PhD}^{1,2,6}$ \\ ${ }^{1}$ Center for Engineering in Medicine/Surgical Services, Massachusetts General Hospital, Harvard \\ Medical School, Boston, Massachusetts \\ ${ }^{2}$ Shriners Hospitals for Children, Boston, Massachusetts \\ ${ }^{3}$ Department of Mechanical Engineering, Massachusetts Institute of Technology, Cambridge, \\ Massachusetts \\ ${ }^{4}$ Division of Plastic Surgery, Massachusetts General Hospital, Harvard Medical School, Boston, \\ Massachusetts \\ ${ }^{5}$ Division of Plastic Surgery, Brigham \& Women's Hospital, Harvard Medical School, Boston, \\ Massachusetts \\ ${ }^{6}$ Department of Biomedical Engineering, Rutgers University, Piscataway, New Jersey
}

\begin{abstract}
While dermal substitutes can mitigate scarring and wound contraction, a significant drawback of current dermal replacement technologies is the apparent delay in vascular ingrowth compared with conventional skin grafts. Herein, we examined the effect of the chemokine stromal cell-derived factor-1 (SDF-1) on the performance of a porous collagen-glycosaminoglycan dermal analog in excisional wounds in mice. C57BL/6 mice with $1 \mathrm{~cm} \times 1 \mathrm{~cm}$ dorsal full-thickness wounds were covered with a collagen-glycosaminoglycan scaffold, followed by four daily topical applications of $1 \mu \mathrm{g}$ SDF-1 or phosphate-buffered saline vehicle. Some animals were also pretreated with five daily doses of $300 \mathrm{mg} / \mathrm{kg}$ granulocyte colony-stimulating factor. Animals treated with SDF-1 and no granulocyte colony-stimulating factor reepithelialized $36 \%$ faster than vehicle controls (16 vs. 25 days), and exhibited less wound contraction on postwounding day 18 ( $35 \%$ greater wound area) plus three-fold longer neoepidermis formed than controls. Conversely, granulocyte colonystimulating factor promoted contraction and no epidermal regeneration. Early (postwounding Day 3) inflammatory cell infiltration in the SDF-1-treated group was $86 \%$ less, while the fraction of proliferating cells (positive Ki67 staining) was $32 \%$ more, when compared with controls. These results suggest that SDF-1 simultaneously delays contraction and promotes reepithelialization and may improve the wound-healing performance of skin substitutes.
\end{abstract}

Healing large skin defects with minimal scarring and contraction remains a significant problem in patients with burns, chronic wounds, and skin cancer. ${ }^{1}$ Scarring and wound contraction are dermal phenomena that can be mitigated by the use of skin grafts and dermal substitutes, such as Integra ${ }^{\mathrm{TM}}$ and Alloderm ${ }^{\mathrm{TM}}$, which provide templates for dermal

(C) 2010 by the Wound Healing Society

Reprint requests: François Berthiaume, PhD, Rutgers University, 599 Taylor Road, Piscataway, NJ 08854, USA. Tel: 11 732-445-4500; Fax: 11 732-445-3753; fberthia@ rci.rutgers.edu. 
regeneration. ${ }^{2}$ In spite of their benefits in burns and reconstructive surgery, a significant drawback of current dermal replacement technologies is the apparent delay in vascular ingrowth compared with conventional skin grafts. ${ }^{3-5}$

Wound healing is a highly coordinated process where cell-cell interactions (homotypic and heterotypic) are important and are mediated, in part, by chemokines, a family of signaling molecules that have chemotactic properties for leukocytes and other cell types, and likely participate in the regulation of angiogenesis, epithelialization, and tissue remodeling phases of wound healing. ${ }^{6}$ The CXC chemokine stromal cell-derived factor-1 (SDF-1/CXCL12), which specifically binds the receptor CXCR4, plays a key role in the trafficking of lymphocytes, ${ }^{7}$ hematopoietic stem cells, and endothelial progenitors. ${ }^{8}$ While the majority of chemokines are inducible, SDF-1 is constitutively expressed in many tissues including the skin. ${ }^{9,10}$ In skin wound healing, recent studies have shown that SDF-1 is down-regulated both at the mRNA and at the protein level within the early granulation tissue, while it is upregulated at the wound margins, particularly in fibroblasts and endothelial cells. ${ }^{11}$

Inflammatory cytokines, such as tumor necrosis factor- $\alpha$, interleukin- 1 , and interferon- $\gamma$, have been shown to decrease SDF-1 expression in fibroblasts. ${ }^{11,12}$

Because SDF-1 expression is reported to be primarily at the wound edges, it is plausible that SDF-1 levels are relatively low over much of the wound area. In light of the various known chemotactic properties of SDF-1 toward stem cells and progenitor cells that may be beneficial to wound healing, we investigated the effect of an exogenous application of SDF-1 on the healing of wounds extending deep into the dermis when used in combination with a dermal skin substitute. We also investigated the effect of systemic granulocyte colony-stimulating factor (GCSF) pretreatment to increase the number of circulating stem cells before SDF-1 application.

\section{MATERIALS AND METHODS}

\section{Materials}

Recombinant mouse CXCL12/SDF-1 $\alpha$ was purchased from R\&D Systems (Minneapolis, $\mathrm{MN}$ ). GCSF was purchased as commercially available Neupogen (Filgrastim) in $300 \mu \mathrm{g} / \mathrm{mL}$ concentration from Amgen (Thousand Oaks, CA).

A 1-mm-thick dermal scaffold consisting of a porous cross-linked collagenglycosaminoglycan (GAG) matrix was prepared by mixing a suspension of bovine collagen and shark-derived chondroitin-6-sulfate, and subjecting the precipitated copolymer to crosslinking by dehydrothermal treatment based on prior established protocols. ${ }^{13}$ This thickness was chosen to match that of murine skin.

\section{Animals}

Male 29-35-day-old wild-type mice (C57BL/6) were purchased from Charles River Laboratories (Wilmington, MA) and maintained in accordance with National Research Council guidelines. Animals were housed in an Association for Assessment and Accreditation of Laboratory Animal Care (AAALAC)-accredited facility at the Shriners Hospitals for Children-Boston, and all procedures on animals were approved by the Subcommittee on Research Animal Care at Massachusetts General Hospital.

\section{Wound model}

Approximately half of the animals in a cohort ( $n=19)$ were pretreated with $300 \mu \mathrm{g} / \mathrm{kg} \mathrm{GCSF}$, given subcutaneously daily for 5 days before surgery. ${ }^{14}$ The remainder $(n=21)$ were given saline instead. One day before surgery, all animals were shaved and depilated (Nair R, 
Church \& Dwight Co., Princeton, NJ). On the day of the surgery (Day 0), the mice were weighed and anesthetized with $60 \mathrm{mg} / \mathrm{kg}$ pentobarbital. The dorsal skin was marked using a standardized $1.0 \mathrm{~cm}^{2}$ square template. A full-thickness wound was created on the dorsal area of the mouse by excising a $1 \mathrm{~cm} \times 1 \mathrm{~cm}$ square of skin (epidermis, dermis, and underlying panniculus carnosus). An equivalent piece of collagen-GAG dermal scaffold (skin substitute) was sutured onto the wound, ensuring that its porous bottom surface was in contact with the wound bed. Then, $1 \mu \mathrm{g}$ SDF-1 in $100 \mu \mathrm{L}$ of phosphate-buffered saline (PBS) was pipetted onto the scaffolds of approximately half of the saline-pretreated $(n=11)$ and half of the GCSF-pretreated animals $(n=10)$. The other animals received the same volume of PBS solution. Benzoin tincture compound (Paddock Laboratories, Minneapolis, $\mathrm{MN}$ ) was applied around the wound margins. Once dry, the wound area was covered with a semiocclusive transparent polyurethane dressing (Tegaderm ${ }^{\mathrm{TM}}$, 3M, St. Paul, MN). Animals received subsequent topical SDF-1 or PBS treatments once a day for 3 additional days by injecting under the polyurethane dressing and on top of the scaffold without disturbing the dressing. More specifically, the skin was punctured with the needle away from the wound area. Then, the needle tip was pushed subcutaneously until located $\sim 1 \mathrm{~cm}$ away from the wound site and under the dressing. The skin was punctured again, allowing the needle to emerge between the skin and the dressing, and slowly moved above the center of the scaffold, where fluid was dispensed.

This created four experimental groups: (a) GCSF+SDF-1 ( $n=10)$; (b) SDF-1 alone ( $n=11$ ); (c) GCSF alone $(n=9)$; and (d) PBS vehicle control $(n=10)$. Three days postsurgery, some animals in each group ( $n=6,6,5$, and 6 , respectively) were euthanized and the wounds were harvested en block including the surrounding skin and underlying tissue areas. The rest of the animals were monitored daily and sacrificed when reepithelialization was evident macroscopically (based on the absence of redness and fluid exudate) on Day 18 postsurgery. Wounds were photographed digitally from a standard height on the day of surgery (Day 0) and the day the animals were sacrificed (Days 3 and 18).

\section{Histological processing}

Excised tissues were fixed in 10\% neutral-buffered formalin for 24 hours and then stored in $70 \%$ alcohol at $4{ }^{\circ} \mathrm{C}$ until final processing. Wound tissues were cut along a midline, embedded in paraffin, processed into 5 - $\mu \mathrm{m}$-thin sections, and stained using the hematoxylin $\&$ eosin $(\mathrm{H} \& \mathrm{E})$ protocol. The histological images were photographed using a Nikon Labophot (Melville, NY) microscope equipped with a Polaroid DMC2 color camera (Concord, MA) using analysis software version $\mathrm{v} 2.1$. Images were taken in the center of each histological section at $\times 4, \times 10$, and $\times 40$ magnifications.

\section{Tissue morphometric analysis}

To determine the macroscopic wound area, the digital macroscopic images were analyzed using NIH ImageJ software v $1.40 \mathrm{~g}$ (ImageJ, NIH, Bethesda, MD). Planimetry was used to calculate the scar area, which was defined as the area devoid of hair growth on Day 18 postsurgery. This value was expressed as a percentage of the initial wound area, which was measured immediately after surgery on Day 0 .

Stained histological sections from Day 18 postsurgery were also analyzed microscopically at 4 magnification using ImageJ software to determine the neoepidermal length and contraction distance. Neoepidermal length was defined as the distance of reepithelialization between the ends of the normal epidermis on either side of the wound. Contraction distance was measured as the distance between the panniculus carnosus in the uninjured normal dermis on either side of the wound. Lateral wound margins in the histological sections were 
determined by the presence of appendages (hair follicles, sweat glands) and a more organized epidermis and dermis.

\section{Immunohistochemistry protocol and analysis}

The paraffin sections from the Day 3 postsurgery wounds were stained for the cell proliferation antigen Ki67, whereas the Day 18 postsurgery wounds were stained for $\alpha$ smooth muscle cell actin ( $\alpha$-SMA) according to previously published protocols. ${ }^{15}$

Ki67 antigen retrieval was accomplished by treatment with Proteinase K (Roche Diagnostics Corp., Indianapolis, IN) and microwaving in $10 \mathrm{mM}$ sodium citrate (pH56), respectively. The primary antibody for Ki67 was from LabVision (Freemont, CA). A biotinylated anti-rat IgG secondary antibody was used in conjunction with a tyramide amplification system (PerkinElmer, Boston, MA). High-power $(\times 40)$ magnification digital images were visualized using Adobe Photoshop CS software (Adobe Systems Incorporated, San Jose, CA). Images of the Ki67-stained wound sections were quantified to determine the number of proliferating cells (brown nuclei) over the entire section using three fields per histological section (one in the middle of the granulation tissue and two on either lateral aspect). The cell proliferation rate was expressed as a percentage of positive nuclei to total nuclei. ${ }^{15}$

For $\alpha$-SMA staining, the deparaffinized histological slides were pretreated with $0.1 \%$ trypsin (Sigma Chemical Co., St. Louis, MO) to facilitate antibody penetration. Endogenous peroxidase was quenched with $3 \%$ hydrogen peroxide (Sigma Chemical Co.). Nonspecific sites were blocked with $1 \%$ goat serum (Sigma Chemical Co.). A monoclonal anti- $\alpha$-SMA antibody from Sigma Chemical Co. was used in conjunction with a biotinylated goat antimouse $\operatorname{IgG}$ secondary antibody (Sigma Chemical Co.) and affinity-purified avidin (Sigma Chemical Co.). The labeling was carried out using an aminoethyl carbazole chromogen kit (Zymed Laboratories Inc., South San Francisco, CA) and the slides were counterstained with Mayer's hematoxylin. Negative controls of each histological section were also performed, which were stained with an anti-myeloma $\operatorname{IgG}_{2 \sigma}$ instead of the primary antibody. Myofibroblasts were identified as $\alpha$-SMA-positive cells if they displayed the reddish brown color for the chromogen with an intensity comparable to that of the vascular smooth muscle cells in the same section. Digital images of the stained sections were obtained at $4 \times$ magnification to measure the relative percentage of the $\alpha$-SMA-positive cell area in the wound area using NIH ImageJ software. ${ }^{16} \mathrm{H} \& \mathrm{E}$ stain was performed to visualize and compare the infiltration of inflammatory cells into the wound area among the animal groups at an early time point (Day 3). The inflammatory cell density was evaluated among the control and the GCSF+SDF-1 animal groups by assessing three fields per histological stained slide (one in the middle of the wound scaffold area and two on either lateral aspect) at $\times 40$ magnification. Inflammatory cells (neutrophils, lymphocytes, and basophils) in each high-powered field image were counted using Adobe Photoshop CS software (Adobe Systems Incorporated).

\section{Statistical analysis}

Results are expressed as mean \pm standard deviation. Unpaired Student's $t$ test (two-tailed) was used to evaluate the significance of differences between groups. A $p<0.05$ was considered statistically significant.

\section{RESULTS}

In this study, we investigated the effect of topically applied SDF- $1 \alpha$ on the wound-healing response in wild-type mice. Each mouse was inflicted one wound consisting of a fullthickness $1 \mathrm{~cm} \times 1 \mathrm{~cm}$ excision on the dorsum area that was grafted with a collagen- 
GAG dermal matrix. The wounds were then covered with a thin silicone sheet dressing $\left(\right.$ Tegaderm $\left.^{\mathrm{TM}}\right)$. Some animals were also systemically administered GCSF, which was used to mobilize stem cells from the bone marrow into the circulation, before wounding.

The animals and their respective wound gross morphology were followed every day postsurgery (Day 0) until wound closure. "Wound closure" was defined as when the wound area no longer exhibited redness and fluid loss (exudate). Reepithelialization of the closed wounds was specifically confirmed by histology on Day 18. By Day 18, all groups treated with SDF-1 and/or GCSF had closed wound areas while the wounds of the PBS vehicle control group were still open (Figure 1). Histological analysis of wound cross-sections at that time point confirmed that all wounds, except for PBS controls, had fully reepithelialized (Figure 2). On average, wounds treated with SDF-1 alone closed within 16 days postwounding, while the GCSF-treated groups took 18 days and the PBS vehicle controls took 25 days to close (Table 1). Thus, SDF-1 treatment accelerated reepithelialization by $36 \%$ compared with PBS vehicle controls.

All wounds contracted to less than $10 \%$ of their initial wound area. Nevertheless, notable differences among the animal groups were seen. Referring back to Figure 1, wounds in the SDF-1 only-treated animals exhibited a clearly visible epithelialized area free of hair at the time of closure, suggesting that a significant amount of new tissue had formed. GCSF-onlytreated animals, on the other hand, contracted almost completely, leaving a narrow "stellate" scar with virtually no remaining hair-free area. Animals treated with a combination of both GCSF and SDF-1 showed in-between behavior. Wound hair-free areas on Day 18 were quantified and normalized to the initial wound area. The results show a significantly greater wound area in the SDF-1 group compared with any other group (Figure 3). This area was approximately $35 \%$ larger than in the control group, suggesting that in the presence of scaffold, SDF-1 inhibited wound contraction. Conversely, GCSF-treated groups (with or without SDF-1) contracted significantly more than the controls, suggesting that GCSF promotes wound contraction.

To further corroborate these macroscopic results, we also measured the contraction distance and neoepidermal length at the microscopic levels on histological sections of wounds harvested on postwounding Day 18. Contraction distance was reduced by approximately $50 \%$ (Figure 4A), while neoepidermal length was increased by over three-fold in the SDF-1treated group compared with the PBS control group (Figure 4B). These results further support the notion that SDF-1 inhibits wound contraction and promotes reepithelialization of scaffoldgrafted wounds.

Because myofibroblasts are often present in contracting wounds, we stained for the myofibroblast marker $\alpha$-SMA in histological wound sections harvested on postwounding Day 18. Representative observations at low magnification $(\times 4)$ are shown in Figure 5, and the percentage of $\alpha$-SMA-positive area relative to the total wound area is reported in Table 2. Although there was high variability in the PBS control group, where wounds had typically not fully reepithelialized, there was consistently more tissue expressing $\alpha$-SMA in the SDF-1 group compared with the GCSF group. In addition, the values for the SDF-1 and SDF-1+GCSF groups were very similar.

As a preliminary investigation of the potential mechanisms of action of SDF-1 on the wound-healing response, we examined some of the cellular events in the scaffold at 3 days postsurgery. We found that scaffolds in SDF-1-treated animals had much less cellular infiltrates (Figure 6), more specifically, there was a decrease of $86 \%$ in the SDF-1-treated group compared with the PBS control group (Figure 7A). Concomitantly, there was an approximately $30 \%$ increase in the number of proliferating cells in the SDF-1-treated group 
relative to the PBS control group (Figure 7B). Further studies are required to investigate the specific cell types recruited into the wound site.

Central wound sections obtained postwounding on Day 18 were stained with Masson's trichrome to visualize the collagen fibers at low magnification in the wound bed and the surrounding tissue area of the various animal groups in order to assess the quality of the scar tissue. It was apparent that the collagen bundle organization and cell density in the scar area of all wound groups were different from the surrounding unwounded normal skin. Focusing on the scar areas, the control group showed clearly less collagen deposition as compared with any of the treated groups (Figure 8). However, there was no apparent difference in the collagen deposition or the orientation of the scar tissue area among the treated groups.

\section{DISCUSSION}

In this study, we found that topically applied SDF-1, when used in combination with a crosslinked collagen-chondroitin sulfate matrix scaffold, delayed wound contraction and led to faster closure (reepithelialization) of a full-thickness excision wound in normal wild-type mice as compared with control animals grafted with the scaffold but otherwise treated with PBS vehicle. More specifically, for a $1 \mathrm{~cm} \times 1 \mathrm{~cm}$ excision wound, the time to wound closure was reduced from 25 to 16 days for SDF-1-treated wounds (Table 1). Similar wounds without scaffolds healed in an 18- to 20-day time period, suggesting that while the scaffold by itself slowed down wound closure, with the addition of SDF-1, wound closure time was restored and even shortened compared with wounds not treated with either scaffold or SDF-1. Furthermore, the addition of SDF-1 reduced wound contraction when compared with the PBS vehicle controls (Figure 3). Thus, SDF-1 may significantly improve the performance of cross-linked collagen-chondroitin sulfate matrix dermal scaffolds by both promoting faster reepithelialization and further delaying wound contraction.

Prior studies have reported that SDF-1 enhances wound healing in various injury models, including the skin, albeit without the use of scaffold biomaterials. For example, reports indicate that skin wounds in dystrophin-deficient mice heal faster than wild-type mice, which correlate with higher levels of SDF-1 as well. ${ }^{17}$ Furthermore, exogenous SDF-1 has been shown to increase endothelial progenitor recruitment in wounds of diabetic mice ${ }^{18}$ and to favor neovascularization in general. ${ }^{19}$ Because SDF-1 is known to be chemotactic for stem cells, ${ }^{20}$ it is also plausible that SDF-1 promotes dermal tissue regeneration by attracting hematopoietic stem cells ${ }^{21}$ and mesenchymal stem cells ${ }^{22,23}$ to the wound site. Furthermore, it has been proposed that SDF-1 may promote the migration of neighboring endothelial progenitor cells and stem cells ${ }^{24}$ into injured tissue, thus accelerating neovascularization. ${ }^{11}$ Recent studies indeed suggest that bone marrow-derived circulating stem cells, either endogenous or injected intravenously, are recruited into the wound site, ${ }^{3,21}$ and differentiate into vascular structures. ${ }^{25}$ Other studies also indicate that SDF-1 promotes keratinocyte proliferation, ${ }^{26}$ which is consistent with the observed faster reepithelialization in the SDF-1treated wounds observed herein.

The fact that SDF-1 facilitated the wound-healing process in the presence of a scaffold raises the question of whether scaffold-SDF-1 interactions may play an important role in the biological response observed. Based on our study, we cannot discern whether there is such an interaction but further experiments are warranted to explore the possibility of cooperativity. It may be that by slowing down wound contraction, the scaffold material may alter the kinetics of the wound-healing response in such a way that it enables SDF-1 to exert an effect. If this is the case, it would be interesting to assess the role of the scaffold in diabetic mice, which have inherently slower wound contraction than wild-type mice. ${ }^{27} \mathrm{It}$ is also plausible that SDF-1 binds the negatively charged chondroitin sulfate in the scaffold 
material, as SDF-1 is positively charged, ${ }^{10}$ with potential beneficial consequences, such as prolonging the half-life and the duration of release of SDF-1 in the wound area.

While we observed reduced wound contraction with SDF-1 within the time frame of the studies reported herein, in a few extra animals, we continued observations of the wounds several weeks after closure and found that they continued to contract (data not shown); thus, SDF-1 appeared to delay but not completely stop the wound contraction process in this particular animal model. The $\alpha$-SMA staining data are in line with this, because positive staining was consistently found in the SDF-1- and GCSF+SDF-1-treated groups (Table 2), suggesting that they were likely undergoing further wound contraction at the time of observation (18 days postwounding). Interestingly, the GCSF-only group consistently had the lowest expression level of $\alpha$-SMA, which suggests that those wounds had fully contracted by that time. $\alpha$-SMA was extremely variable in the controls, which still had open wounds on Day 18. In some instances (as shown in Figure 5A), the expression level was very high, which may be due to the lack of epidermal signals, because the literature data suggest that epithelial-derived factors inhibit fibroblast-mediated wound contraction. ${ }^{28}$

One study indicated that blocking endogenous SDF-1 resulted in increased reepithelialization and decreased eosinophil infiltration in second-degree dermal burn wounds 5 days postwounding, although complete reepithelialization of the burn wounds had not occurred. ${ }^{29}$ An interesting fact is that while SDF-1 is known to be chemotactic for cells expressing CXCR $4,{ }^{30,31}$ recent studies also indicate that at high concentrations, SDF-1 repels many CXCR4-expressing cell types. ${ }^{32,33}$ Thus, it is plausible that high levels of SDF-1 could have similar effects to blocking SDF-1 in the wound-healing context. We did observe a decrease in the inflammatory response in the SDF-1-treated groups at 3 days postwounding (Figure 6), and various studies indicate that blocking CXCR4 inhibits the recruitment of inflammatory cells in vivo. ${ }^{34}$ Prior literature data from fetal wound healing studies also suggest that the lack of inflammatory cell recruitment into the wound is a hallmark of fetal regenerative wound healing; as the embryonic immune system develops, the inflammatory response to injury becomes more prominent, and wound healing shifts to healing by scar formation. ${ }^{35-37}$ Thus, it would be interesting to ascertain whether the decreased inflammatory response due to SDF-1 is an important contributor to the improved wound healing observed here.

Some experimental groups included systemic GCSF pretreatment, which promotes the release of hematopoietic cells from the bone marrow into the circulation. ${ }^{38} \mathrm{We}$ found that GCSF promoted faster wound closure (18 days vs. 25 days for the PBS control group; see Table 1) in scaffold-grafted wounds, but the effect appeared to be entirely mediated by wound contraction (Figures 1, 3, and 4). While the reasons for this were not explored here, it is plausible that GCSF mobilizes bone marrow cells that promote wound contraction. For example, prior experimental results have pointed out the existence of circulating fibrocytes that can home into the wound site. ${ }^{39}$ Thus, understanding the impact of GCSF on the dynamics of cells both in the circulation and in the wound site would require further study. However, because inhibition of wound contraction in rodents correlates to better wound healing by reduced scar formation in human wounds, ${ }^{40}$ these results suggest that GCSF may be detrimental for the regeneration of dermal wounds.

In conclusion, the results from our experiments herein suggest that topically applied SDF-1, when used in conjunction with a collagen-GAG dermal scaffold, simultaneously inhibits wound contraction and stimulates reepithelialization in a mouse full-thickness excision skin wound model. We propose that incorporating SDF-1 into skin substitutes may significantly improve their wound-healing performance, especially in functional areas where wound contraction and scar formation may be detrimental. Consequently, the SDF-1-treated skin 
substitute may be an effective approach to stimulate wound closure and quality tissue formation in poorly healing tissues. Additional studies will be necessary to determine the optimal dosage and administration schedule of SDF-1 to maximize the wound-healing benefits. Investigation of the underlying mechanisms of action, including the possible roles of SDF-1-mediated stem cell recruitment and modulation of the inflammatory response would greatly help in achieving this goal. Further studies are also needed to investigate the performance of SDF-1-treated-dermal scaffolds in larger wound areas, including those that require coverage with split-thickness skin grafts.

\section{Acknowledgments}

Financial support received from the Deshpande Center for Technological Innovation at M.I.T., the Shriners Hospitals for Children, and the National Institutes of Health (1R21AR056446) is gratefully acknowledged. The authors are also grateful to Dr. Roderick Bronson, Michael Maier, and Michael Xiang for their help with interpretation of wound histology, wound photography, and providing image processing tools, respectively. The authors would also like to thank Dr. Ioannis V. Yannas for providing collagen and GAG materials and valuable discussions, Dr. Myron Spector for helping with the $\alpha$-SMA staining, and Dr. Robert S. Langer for constructive feedback and discussion.

\section{Glossary}

$\begin{array}{ll}\text { a-SMA } & \text { Alpha-smooth muscle actin } \\ \text { bFGF } & \text { Basic fibroblast growth factor } \\ \text { CXCR4 } & \text { Chemokine (C-X-C motif) receptor 4 } \\ \text { GCSF } & \text { Granulocyte colony-stimulating factor } \\ \text { H\&E } & \text { Hematoxylin and eosin } \\ \text { PBS } & \text { Phosphate-buffered saline } \\ \text { SDF-1 } & \text { Stromal cell-derived factor-1 }\end{array}$

\section{REFERENCES}

1. Rhett JM, Ghatnekar GS, Palatinus JA, O'Quinn M, Yost MJ, Gourdie RG. Novel therapies for scar reduction and regenerative healing of skin wounds. Trends Biotechnol. 2008; 26:173-80. [PubMed: 18295916]

2. Auger FA, Berthod F, Moulin V, Pouliot R, Germain L. Tissue-engineered skin substitutes: from in vitro constructs to in vivo applications. Biotechnol Appl Biochem. 2004; 39(Part 3):263-75. [PubMed: 15154837]

3. Metcalfe AD, Ferguson MW. Tissue engineering of replacement skin: the crossroads of biomaterials, wound healing, embryonic development, stem cells and regeneration. J R Soc Interface. 2007; 4:413-37. [PubMed: 17251138]

4. Bargues L, Boyer S, Leclerc T, Duhamel P, Bey E. Incidence and microbiology of infectious complications with the use of artificial skin Integra in burns. Ann Chir Plast Esthet. 2009; 54:533-9. [PubMed: 19223101]

5. Orgill DP. Excision and skin grafting of thermal burns. N Engl J Med. 2009; 360:893-901. [PubMed: 19246361]

6. Zaja-Milatovic S, Richmond A. CXC chemokines and their receptors: a case for a significant biological role in cutaneous wound healing. Histol Histopathol. 2008; 23:1399-407. [PubMed: 18785122]

7. Kim CH, Broxmeyer HE. Chemokines: signal lamps for trafficking of $\mathrm{T}$ and $\mathrm{B}$ cells for development and effector function. J Leukoc Biol. 1999; 65:6-15. [PubMed: 9886241]

8. Stellos K, Gawaz M. Platelet interaction with progenitor cells: potential implications for regenerative medicine. Thromb Haemost. 2007; 98:922-9. [PubMed: 18000594] 
9. Pablos JL, Amara A, Bouloc A, Santiago B, Caruz A, Galindo M, Delaunay T, Virelizier JL, Arenzana-Seisdedos F. Stromal-cell derived factor is expressed by dendritic cells and endothelium in human skin. Am J Pathol. 1999; 155:1577-86. [PubMed: 10550315]

10. Shirozu M, Nakano T, Inazawa J, Tashiro K, Tada H, Shinohara T, Honjo T. Structure and chromosomal localization of the human stromal cell-derived factor 1 (SDF1) gene. Genomics. 1995; 28:495-500. [PubMed: 7490086]

11. Toksoy A, Muller V, Gillitzer R, Goebeler M. Biphasic expression of stromal cell-derived factor-1 during human wound healing. Br J Dermatol. 2007; 157:1148-54. [PubMed: 17941943]

12. Fedyk ER, Jones D, Critchley HO, Phipps RP, Blieden TM, Springer TA. Expression of stromalderived factor-1 is decreased by IL-1 and TNF and in dermal wound healing. J Immunol. 2001; 166:5749-54. [PubMed: 11313418]

13. O'Brien FJ, Harley BA, Yannas IV, Gibson L. Influence of freezing rate on pore structure in freeze-dried collagen-GAG scaffolds. Biomaterials. 2004; 25:1077-86. [PubMed: 14615173]

14. Petit I, Szyper-Kravitz M, Nagler A, Lahav M, Peled A, Habler L, Ponomaryov T, Taichman RS, Arenzana-Seisdedos F, Fujii N, Sandbank J, Zipori D, Lapidot T. G-CSF induces stem cell mobilization by decreasing bone marrow SDF-1 and up-regulating CXCR4. Nat Immunol. 2002; 3:687-94. [PubMed: 12068293]

15. Pietramaggiori G, Scherer SS, Mathews JC, Alperovich M, Yang HJ, Neuwalder J, Czeczuga JM, Chan RK, Wagner CT, Orgill DP. Healing modulation induced by freeze-dried platelet-rich plasma and micronized allogenic dermis in a diabetic wound model. Wound Repair Regen. 2008; 16:218-25. [PubMed: 18318807]

16. Kinner B, Pacicca DM, Gerstenfeld LC, Lee CA, Einhorn TA, Spector M. Expression of smooth muscle actin in cells involved in distraction osteogenesis in a rat model. J Orthop Res. 2003; 21:20-7. [PubMed: 12507576]

17. Straino S, Germani A, Di Carlo A, Porcelli D, De Mori R, Mangoni A, Napolitano M, Martelli F, Biglioli P, Capogrossi MC. Enhanced arteriogenesis and wound repair in dystrophin-deficient mdx mice. Circulation. 2004; 110:3341-8. [PubMed: 15545520]

18. Gallagher KA, Liu ZJ, Xiao M, Chen H, Goldstein LJ, Buerk DG, Nedeau A, Thom SR, Velazquez OC. Diabetic impairments in NO-mediated endothelial progenitor cell mobilization and homing are reversed by hyperoxia and SDF-1 alpha. J Clin Invest. 2007; 117:1249-59. [PubMed: 17476357]

19. Yamaguchi J, Kusano KF, Masuo O, Kawamoto A, Silver M, Murasawa S, Bosch-Marce M, Masuda H, Losordo DW, Isner JM, Asahara T. Stromal cell-derived factor-1 effects on ex vivo expanded endothelial progenitor cell recruitment for ischemic neovascularization. Circulation. 2003; 107:1322-8. [PubMed: 12628955]

20. Son BR, Marquez-Curtis LA, Kucia M, Wysoczynski M, Turner AR, Ratajczak J, Ratajczak MZ, Janowska-Wieczorek A. Migration of bone marrow and cord blood mesenchymal stem cells in vitro is regulated by stromal-derived factor-1-CXCR4 and hepatocyte growth factor-c-met axes and involves matrix metalloproteinases. Stem Cells. 2006; 24:1254-64. [PubMed: 16410389]

21. Cottler-Fox MH, Lapidot T, Petit I, Kollet O, DiPersio JF, Link D, Devine S. Stem cell mobilization. Hematology Am Soc Hematol Educ Program. 2003:419-37. [PubMed: 14633793]

22. Fu X, Fang L, Li X, Cheng B, Sheng Z. Enhanced wound-healing quality with bone marrow mesenchymal stem cells autografting after skin injury. Wound Repair Regen. 2006; 14:325-35. [PubMed: 16808812]

23. Nakagawa H, Akita S, Fukui M, Fujii T, Akino K. Human mesenchymal stem cells successfully improve skin-substitute wound healing. Br J Dermatol. 2005; 153:29-36. [PubMed: 16029323]

24. Askari AT, Unzek S, Popovic ZB, Goldman CK, Forudi F, Kiedrowski M, Rovner A, Ellis SG, Thomas JD, DiCorleto PE, Topol EJ, Penn MS. Effect of stromal-cell-derived factor 1 on stemcell homing and tissue regeneration in ischaemic cardiomyopathy. Lancet. 2003; 362:697-703. [PubMed: 12957092]

25. Sasaki M, Abe R, Fujita Y, Ando S, Inokuma D, Shimizu H. Mesenchymal stem cells are recruited into wounded skin and contribute to wound repair by transdifferentiation into multiple skin cell type. J Immunol. 2008; 180:2581-7. [PubMed: 18250469] 
26. Florin L, Maas-Szabowski N, Werner S, Szabowski A, Angel P. Increased keratinocyte proliferation by JUN-dependent expression of PTN and SDF-1 in fibroblasts. J Cell Sci. 2005; 118(Part 9):1981-9. [PubMed: 15840658]

27. Scherer SS, Pietramaggiori G, Matthews J, Perry S, Assmann A, Carothers A, Demcheva M, Muise-Helmericks RC, Seth A, Vournakis JN, Valeri RC, Fischer TH, Hechtman HB, Orgill DP. Poly- $N$-acetyl glucosamine nanofibers: a new bioactive material to enhance diabetic wound healing by cell migration and angiogenesis. Ann Surg. 2009; 250:322-30. [PubMed: 19638916]

28. Eisinger M, Sadan S, Silver IA, Flick RB. Growth regulation of skin cells by epidermal cellderived factors: implications for wound healing. Proc Natl Acad Sci USA. 1988; 85:1937-41. [PubMed: 2450352]

29. Avniel S, Arik Z, Maly A, Sagie A, Basst HB, Yahana MD, Weiss ID, Pal B, Wald O, Ad-El D, Fujii N, Arenzana-Seisdedos F, Jung S, Galun E, Gur E, Peled A. Involvement of the CXCL12/ CXCR4 pathway in the recovery of skin following burns. J Invest Dermatol. 2006; 126:468-76. [PubMed: 16385346]

30. Rafii DC, Psaila B, Butler J, Jin DK, Lyden D. Regulation of vasculogenesis by platelet-mediated recruitment of bone marrow-derived cells. Arterioscler Thromb Vasc Biol. 2008; 28:217-22. [PubMed: 18096826]

31. Miller RJ, Banisadr G, Bhattacharyya BJ. CXCR4 signaling in the regulation of stem cell migration and development. J Neuroimmunol. 2008; 198:31-8. [PubMed: 18508132]

32. Vianello F, Olszak IT, Poznansky MC. Fugetaxis: active movement of leukocytes away from a chemokinetic agent. J Mol Med. 2005; 83:752-63. [PubMed: 16142473]

33. Poznansky MC, Olszak IT, Foxall R, Evans RH, Luster AD, Scadden DT. Active movement of T cells away from a chemokine. Nat Med. 2000; 6:543-8. [PubMed: 10802710]

34. Petty JM, Sueblinvong V, Lenox CC, Jones CC, Cosgrove GP, Cool CD, Rai PR, Brown KK, Weiss DJ, Poynter ME, Suratt BT. Pulmonary stromal-derived factor-1 expression and effect on neutrophil recruitment during acute lung injury. J Immunol. 2007; 178:8148-57. [PubMed: 17548653]

35. Mescher AL, Neff AW. Regenerative capacity and the developing immune system. Adv Biochem Eng Biotechnol. 2005; 93:39-66. [PubMed: 15791943]

36. Yang GP, Lim IJ, Phan TT, Lorenz HP, Longaker MT. From scarless fetal wounds to keloids: molecular studies in wound healing. Wound Repair Regen. 2003; 11:411-8. [PubMed: 14617279]

37. Yang L, Scott PG, Giuffre J, Shankowsky HA, Ghahary A, Tredget EE. Peripheral blood fibrocytes from burn patients: identification and quantification of fibrocytes in adherent cells cultured from peripheral blood mononuclear cells. Lab Invest. 2002; 82:1183-92. [PubMed: 12218079]

38. De Clercq E. The AMD3100 story: the path to the discovery of a stem cell mobilizer (Mozobil). Biochem Pharmacol. 2009; 77:1655-64. [PubMed: 19161986]

39. Abe R, Donnelly SC, Peng T, Bucala R, Metz CN. Peripheral blood fibrocytes: differentiation pathway and migration to wound sites. J Immunol. 2001; 166:7556-62. [PubMed: 11390511]

40. Yannas IV. Studies on the biological activity of the dermal regeneration template. Wound Repair Regen. 1998; 6:518-23. [PubMed: 9893171] 


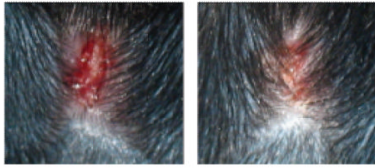

Saline injection \& Saline Application

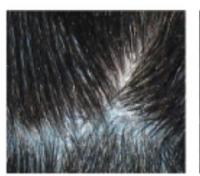

GCSF injection \& Saline Application

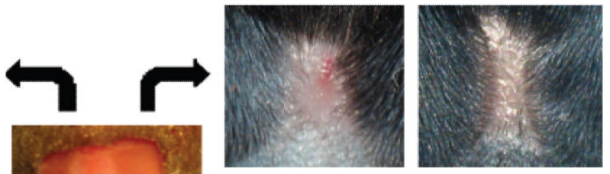

Saline injection \& SDF-1 Application
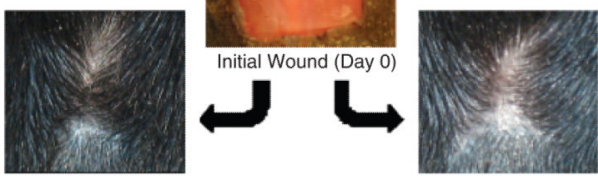

GCSF injection \& SDF-1 Application

Figure 1.

Gross morphology of skin wounds grafted with a collagen-GAG scaffold on Day 18 postwounding. Two representative animals are shown for each group. 

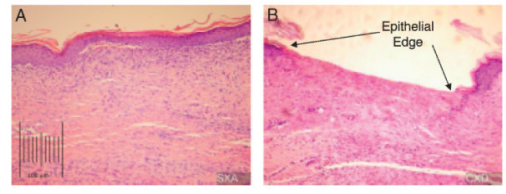

Figure 2.

Wound cross-section harvested on Day 18 postwounding and stained with H\&E. (A) SDF-1treated wound showing intact epidermis over the wound. (B) Control (PBS-treated) wound showing break in the epithelium. 


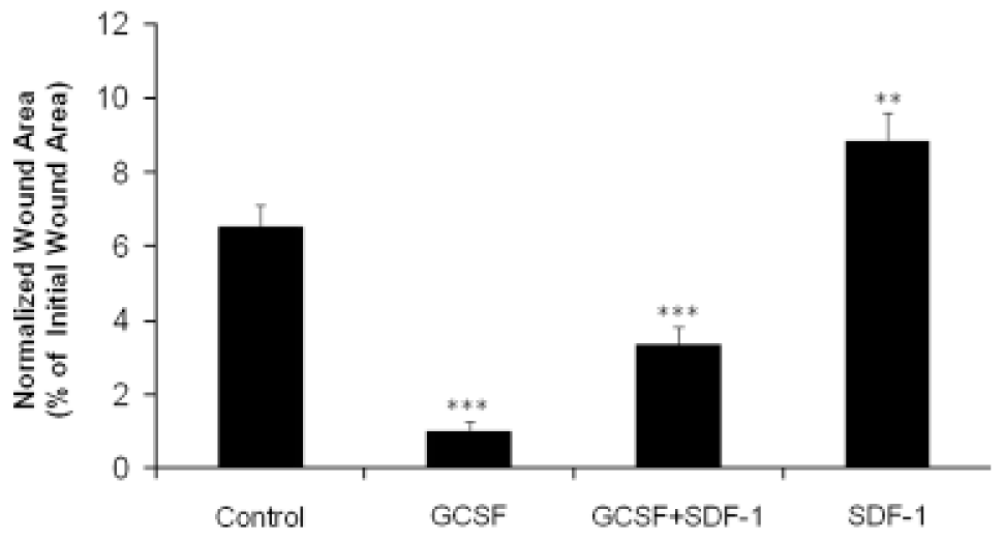

Figure 3.

Quantified wound areas on Day 18 postwounding. Data shown are average \pm SD of the hairfree areas in the groups shown in Figure 1 above. $N=4-5$ mice per group. $* * p<0.001 ; * * * p$ $<0.001$ compared with the control, respectively. 

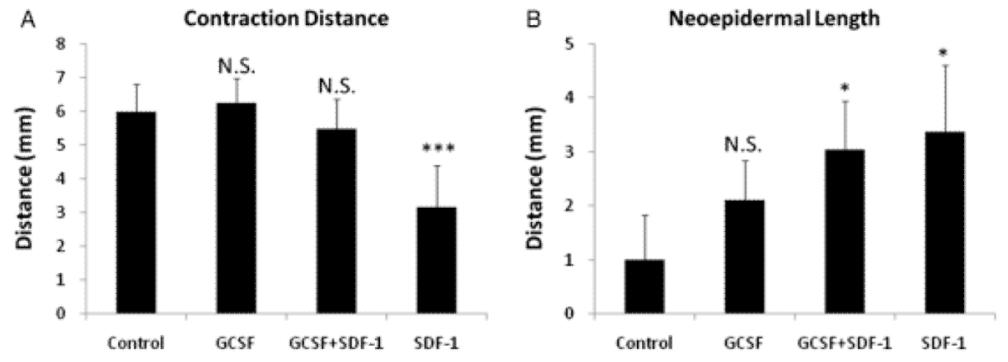

Figure 4.

Contraction distance (A) and neoepidermal length (B) measured on Day 18 postwounding. ${ }^{*} p<0.05$; *** $p<0.001$ compared with the control. In (A), GCSF and SDF-1 groups are also different from each other at a level of $p<0.001$. $N=4-5$ mice per group. NS: not significantly different from the control. 

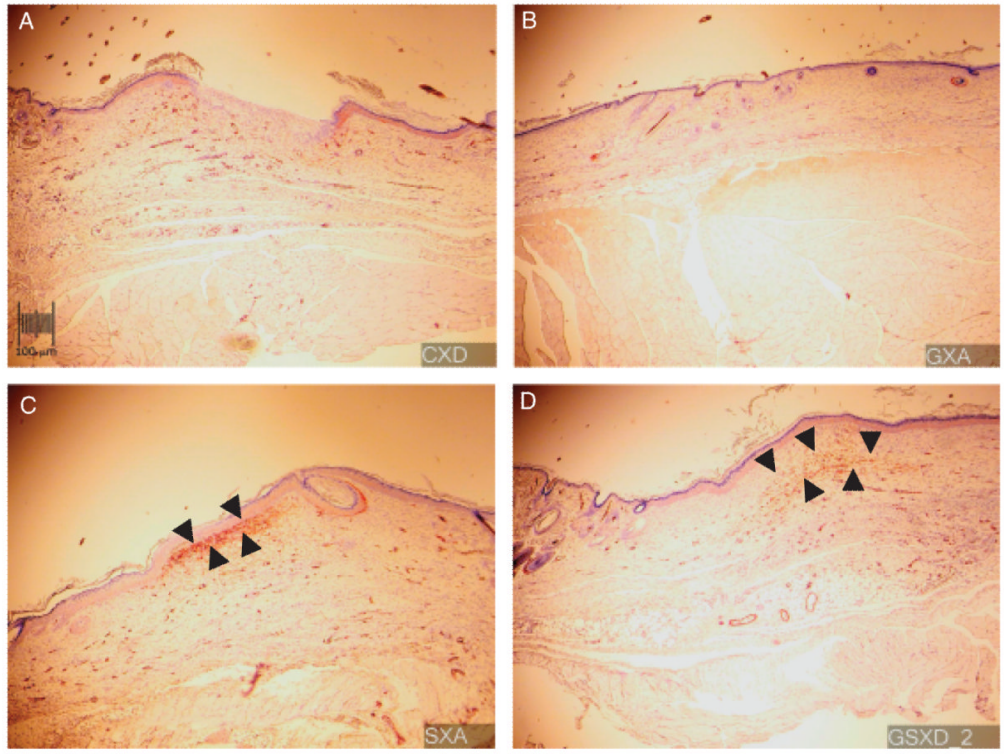

Figure 5.

$\alpha$-Smooth muscle cell actin ( $\alpha$-SMA) distribution in wound cross-sections on Day 18. (A) Control; (B) GCSF only; (C) SDF-1 only; and (D) GCSF+SDF-1. Note that positive staining of $\alpha$-SMA (not visible in the GCSF-only group) appears as a reddish brown stain on the tissue section and is pointed out by arrowheads. Bar $=100 \mu \mathrm{m}$. 


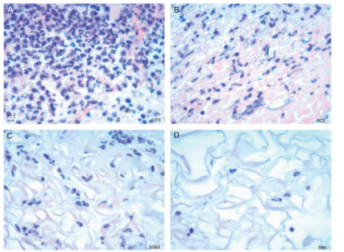

Figure 6.

Cellular infiltrate seen in H\&E-stained wound cross-sections on Day 3 postwounding. (A) Control; (B) GCSF only; (C) GCSF+SDF-1; and (D) SDF-1 only. Bar=10 $\mu \mathrm{m}$. 


$$
\text { I.IIIII }
$$

Figure 7.

Quantification of number of recruited cells in scaffold on Day 3 postwounding. (A) Cell number per high-power field. Data shown are average \pm SD. $N=5-6$ mice per group. $* * * p<$ 0.001 compared with the control. (B) Fraction of Ki67-positive cells normalized to the total cell number in the center of the scaffold. Data shown are average \pm SD. $N=5-6$ mice per group. ${ }^{*} p<0.05$ compared with the control. 

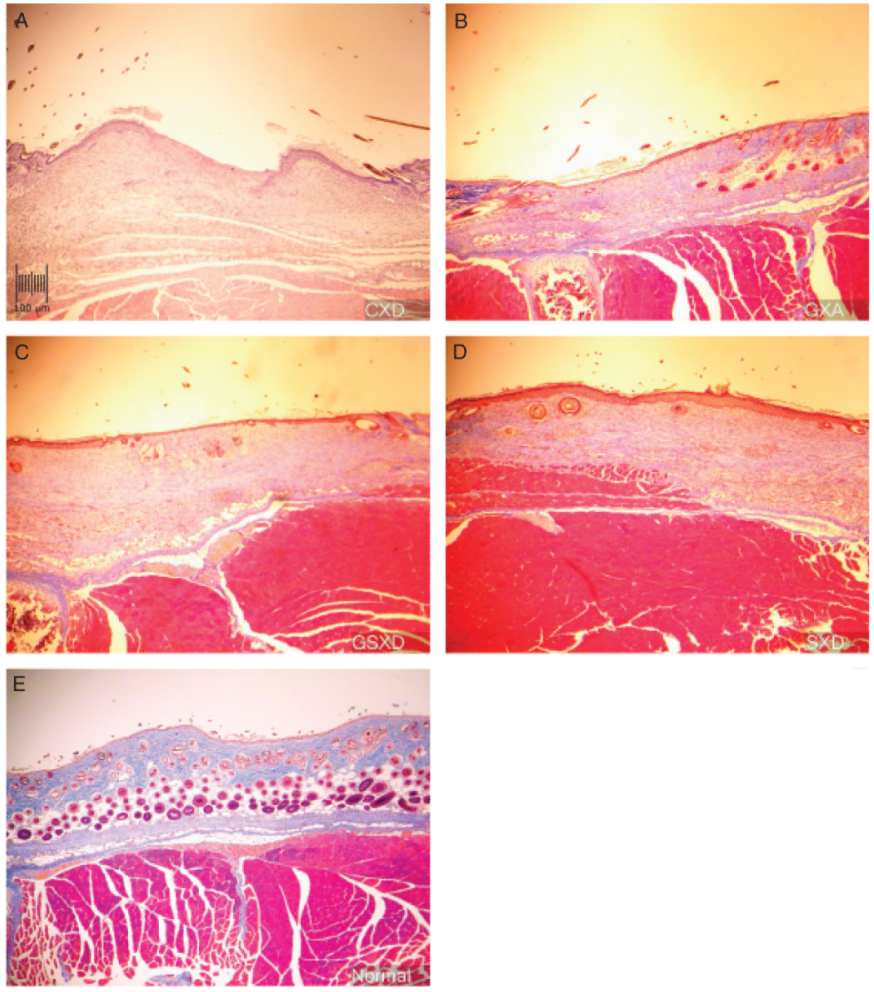

Figure 8.

Appearance of Masson's trichrome-stained cross-sections showing collagen fiber organization. (A) Control; (B) GCSF only; (C) GCSF+SDF-1; (D) SDF-1 only; and (E) normal skin. Wound cross-sections are from Day 18 postwounding. Bar $=100 \mu \mathrm{m}$. 
Table 1

Closure time for $1 \mathrm{~cm} \times 1 \mathrm{~cm}$ full-thickness wounds ${ }^{\dagger}$

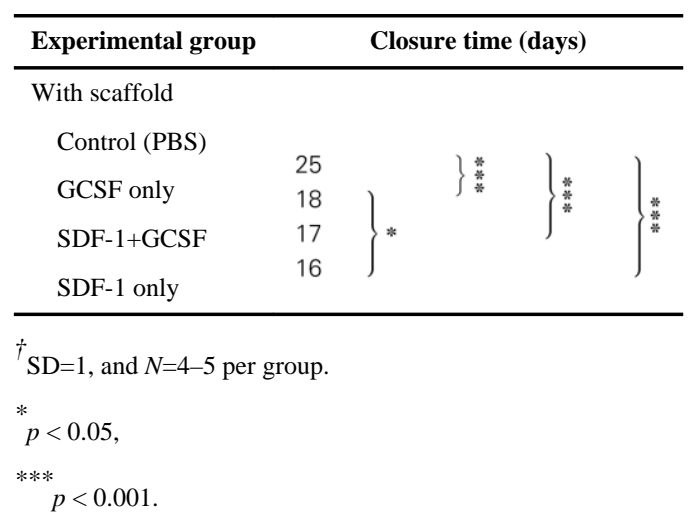


Table 2

Fraction of tissue positively stained for $\alpha$-smooth muscle actin ${ }^{\dagger}$

\begin{tabular}{lc}
\hline Experimental group & \multicolumn{1}{c}{ Area $(\%)$} \\
\hline Control (PBS) & $12.4 \pm 13.0$ \\
GCSF only & $5.2 \pm 1.1$ \\
SDF-1+GCSF & $13.2 \pm 8.4$ \\
SDF-1 only & $14.3 \pm 5.5(p<0.05$ vs. GCSF only $)$ \\
\hline
\end{tabular}

${ }^{\dagger}$ Data shown are average $\pm \mathrm{SD}$, and $N=4-5$ per group. 